cerca do not retain the $S$ bend, although, as Monchadsky and $\mathrm{Skoblo}^{3}$ noted, some food residues do remain in the intestine. The disappearance of the $S$ bend in Schistocerca may account for the normal retention of residual food through inability to produce discrete fæcal pellets. If the locust is poisoned by means of a benzene hexachloride sandwich ${ }^{4}$ the entire contents of the intestine may be ejected, at first as discrete pellets and finally as a continuous rod, which suggests that the quantity of food in the intestine normally controls the formation of the $S$ bend.

Opening into the anterior end of the midgut are six cæca; each cæcum consists of an anterior and a posterior arm. In Locusta intestinal contents pass into both arms (Figs. $2 c$ and $d$ ) and sections cut through the cæca show a peritrophic membrane extending into them. In Schistocerca it is found that only the posterior arms of the cæca contain the intestinal contents (Figs. $2 a$ and $b$ ), the anterior arms remaining unfilled; a peritrophic membrane is found in the posterior arm. The significance of this difference is at present unknown.

\section{Derex Goodhun*}

Department of Zoology,

Imperial College,

London, S.W.7.

* Present address: Trinity College, Dublin.

2 Goodhue, D., Radiography, 263 (1958).

${ }^{2}$ Albrecht, F. O., Anatomy of the Migratory Locust (Athlone Press, London, 1952).

${ }^{3}$ Monchadsky and Skoblo, in Uvarov, B. P., Trans. Roy. Soc., 99, 1, 1 (1948).

Campbell and Filmer, Trans. Fourth Intern. Cong. Ent. 523 (1929).

\section{Feeding Adult Mosquitoes on Solid Sugars}

That mosquitoes may feed on flowers and sources of food other than blood has been observed many times. Notable among these observations are those of Wesen. borg-Lund ${ }^{1}$, Haeger ${ }^{2}$, West and Jenkins ${ }^{3}$, and Sandholm and Prices. Mosquitoes which visit flowers in greatest numbers are various species of Aedes. According to most of the observations recorded, the food consumed is liquid or semi-liquid. The only reference to indicate that mosquitoes may be able to feed on dry food was found in a paper by Downs and Arizmendi ${ }^{5}$ on colonization of Mexican anophelines. These two authors substituted powdered sugar for honey solutions which they normally supplied to the colonies and noted that females more readily took blood after having fed on powdered sugar. They did not further elaborate on this part of their work, and there was no mention of how the powdered sugar was presented to the mosquitoes.

Interest in the ability of mosquitoes to feed on solid sugars was raised by a recent chance observation made by me during the course of other experiments. A female Culex tarsalis Coquillett was observed to probe the nearly dry remains of an insect smashed on the windshield of an automobile. This female probed so persistently for about $0.5 \mathrm{~h}$ that an experiment was conceived to test the ability of mosquitoes to feed on dry or nearly dry material.

In an initial test, glass slides were coated with syrupy sucrose solutions to which had been added ordinary food colours. $C$. tarsalis readily ingested this sticky material and the colour of the syrup soon became apparent in their bodies. The slides were thon air-dried for several days at room temperature, until the sugar completely crystallized. This is a variation of the technique used by Bartlett ${ }^{6}$ to examine dry sugar ingestion by parasitic Hymenoptera. Mosquitoes were placed in glass vials, the open ends of which were covered with the prepared slides placed sugar. coated side down, or towards the mosquitoes. Observations on feeding were made by placing the assembly under a dissecting microscope so that the manipulations of the mouth parts could be seen through the glass. Cover-slips were substituted for the slides when observations were made at greater magnifications with a compound microscope.

The technique described here has enabled me to observe many male and female mosquitoes feeding on solidified, dry sugar. A secretion flows from the mouth parts of the mosquito, and the sugar is ingested in solution. Individuals have been observed to feed for as long as 30 min without apparent diminution of the flow of secretion. The coloured sugar solution appeared to move from the periphery of the labella, across its surface and into a central groove. The food colour could be seen to accumulate within the abdomen during the feeding: process. Dissection showed that the coloured material accumulated in the œsophageal diverticula.

The removal of the sugar during feeding left clear spots on the slides or cover glasses. Forty or fifty mosquitoes, placed in a small cage, were able to remove nearly all the dry sugar from a heavily coated slide in $2-3$ days. A source of water was available in the cage at all times. There appeared to be no regurgitation in the mosquitoes under test since previously ingested food colours were not noticeable in the secretion when the mosquitoes were later fed on uncoloured sugar crystals. This is not regarded as conclusive evidence, however.

It has been customary to describo mosquitoes as having piercing mouth parts. According to these observations mosquitoes have sponging mouth parts as well. The manner in which the mosquitoes dissolve and ingest dry sugar from the glass slides resembles the manner in which houseflies were observed to ingest sugar from slides prepared in the same way.

The species of mosquitoes so far tested for ability to feed on crystallized sugar include the following: $C$. tarsalis, Culex pipiens L., Culiseta inornata (Williston), Culiseta incidens (Thomson), Anopheles freeborni Aitken, Aedes sierrensis (Ludlow), Aedes aegypti (L.), and Aedes taeniorhynchus (Wiedemann).

Many individuals of the different species of Culex and Culiseta which have been tested readily fed on the dry sugars, while species of Aedes and Anopheles which were tested were not avid feeders on this material.

The fact that there is a flow of secretion, or secretions, through the tips of the mouth parts during solid sugar feeding may have practical application in certain kinds of diagnostic and nutritional studies. The fluids which flow to the tips of the mouth parts for dissolving food may be collected and examined for pathogens. Burtt? , for example, has examined the saliva of tsetse flies for the presence of trypanosomes. He collected the saliva by interposing microscope slides between the flies and the laboratory animals which they attempted to bite. Dr. M. M. J. Lavoipierre, Hooper Foundation, University of California College of Medicine, San Francisco, is at present trying the dry sugar feeding method to study the release of filarial worms from mosquitoes. I have initiated an investigation of the feeding habits of field mosquitoes in relation to the kinds of substrates on which they rest.

I thank S. F. Bailey and Dr. M. M. J. Lavoipierre for advice. This work was supported in part by U.S. Public Health Service grant $E 2831$.

\section{Donald A. Eltason}

University of California, Davis, California.

' Wesenberg-Lund, C., Mem. de L'Acad. Royale des Sci. et des Lettres de Danemark, eighth series, 7 , No. 1, 210 (1921).

2 Haeger, James S., Mosq. News, 15 (1), 21 (1955).

${ }^{3}$ West, A. S., and Jenkins, D. W., Mosq. News, 11 (4), 217 (1951),

4 Sandholm, H. A., and Price, R. D., Mosq. News, 22 (4), 346 (1962).

- Downs, W. G., and Arizmendi, A., Rev. Inst. Sal. Enf. Trop. Mex., 12, 21 (1951).

- Bartlett, B. R., J. Econ. Entomol., 55 (5), 749 (1962).

'Burtt, E., Ann. Trop. Med. and Parasit., 40, 141 (1946). 